Key words: Dementia, Depression, Elderly, Community, Prevalence, Follow-up, Incidence.

\title{
The ZARADEMP Project on the incidence, prevalence and risk factors of dementia (and depression) in the elderly community: I. The context and the objectives
}

Antonio Lobo, MD*
Pedro Saz, MD*
Guillermo Marcos, MD**
José-Luis Día, MD***
Concepción De-la-Cámara, MD*
Tirso Ventura, MD***
José Angel Montañés, MD*
Antonio Lobo-Escolar, MD***
Sergio Aznar, MD*
and the ZARADEMP Workgroup

* Servicio de Psiquiatría and Departamento de Medicina y Psiquiatría, Facultad de Medicina of the Universidad de Zaragoza and Hospital Clínico Universitario

** Departamento de Medicina Preventiva y Salud Pública, Facultad de Medicina of the Universidad de Zaragoza and Hospital Clínico Universitario

*** Servicio de Psiquiatría, Hospital Universitario Miguel Servet. Zaragoza

SPAIN

ABSTRACT - Background and Objectives: The public health dimension of the problem of dementia and depression in the elderly population is well documented, but epidemiological data are generally considered to be insufficient and, at times, contradictory. This paper identifies relevant research areas for the ZARADEMP Project, which follows the Zaragoza Study (or ZARADEMP 0) and is part of both EURODEM and EURODEP Studies.

Methods: Review of the literature. Hypotheses emerging in previous studies of this research group.

Results: The following relevant objectives to study in relation to dementia (and depression) have been identified: a) potential variations over time in the prevalence rate; b) provision of reliable estimations of incidence rates, specific for age and gender; c) data about the course and natural history of so called "mild cognitive deficit"; d) association between hypothesized risk factors and cases of dementia (and depression) and its most frequent 
subtypes; and e) testing of hypotheses related to the overlap between dementia and depression and, specifically, to what extent depression has an increased risk for DAT. Other objectives of the study are also reviewed, in particular the cross-cultural comparison of findings in Zaragoza and in other European cities incorporated in both EURODEM and EURODEP Studies. The importance of maintaining good, contemporary methodological standards is emphasized.

Conclusions: A number of relevant research areas in the epidemiology of both dementia and depression in the elderly have been identified. Case-control studies based on incident cases of dementia of the Alzheimer's type (DAT) to adequately assess risk factors seem particularly timely.

\section{Introduction: prevalence and incidence of dementia}

Classical epidemiological studies have suggested that dementia and depression in the elderly pose a major public health problem (Copeland et al. 1987, Mellow 2003). However, a high proportion of mental disorder cases in the community remain untreated (Cole et al. 1999). This was also suggested by the Zaragoza Study, which was the first psychiatric report about the prevalence of dementia and depression in a Spanish speaking country, but also in Southern Europe, which investigated a representative community sample of the elderly with standardized methods of assessment specifically developed for this age group, as well as standardized diagnostic criteria and case levels of illness (Lobo et al. 1995).

While prevalence studies of dementia are abundant, the stability of rates of dementia in the same geographical area has rarely been addressed (Rocca et al. 1998). The ZARADEMP Project follows the Zaragoza Study, which we now call ZARADEMP " $O$ ". Its first objective was to test hypotheses related to potential variations over time in the prevalence rate of dementia that might eventually be traced to environmental circumstances. It was also designed to provide reliable estimations of incidence rates of dementia, specific for age and gender (Lobo et al. 1992). We observed in the follow-up of ZARADEMP " 0 " the exponential increase of the incidence rate with the increase in age reported by most authors (Lobo et al. 1997, Rocca et al. 1998, Di Carlo et al. 2002, Jorm and Jolley 1998). However, we also reported a slowing down of the acceleration of rates in the very old. This slowing down needs clarification (Gao et al. 1998), since the low numbers in the numerator in several studies including ours could account for the low rate in this age group (McGee and Brayne 2001). A third objective of the Project was to document the course and natural history of so called "mild cognitive deficit". This is a subject of recent interest in view of the reported high conversion rate into dementia (Petersen et al. 2001).

\section{Risk factors of dementia: the main objective}

The principal objective of the ZARADEMP Project was to document the association 
between hypothesized risk factors and cases of dementia and its most frequent subtypes, dementia of the Alzheimer's type (DAT) and vascular dementia (VD), so that preventive measures might eventually be instituted (Lobo et al. 1992). In relation to DAT, only an increasing age, the presence of the apolipoprotein-epsilon4 allele, particularly for late-onset DAT, familial aggregation in cases and Down's syndrome are considered to be firmly established risk factors (McDowell 2001). The finding about the steep increase in the prevalence of Alzheimer's type disease with age is the most consistent one in the international literature (Hofman et al. 1991, Jorm et al. 1987). Therefore, attention might be drawn to the null hypothesis and its implications, namely, that cognitive disturbances identified in the elderly might be viewed as a manifestation of senescence in which specific extrinsic influences are unnecessary to account for the pathology observed. However, this notion has to be immediately qualified. Even if age is the most important risk factor for DAT, it may conceal the effect of other weaker risk factors in population studies. Wide variation of genetic and environmental factors that can influence primary degenerative dementia have been identified (Van Duijn and Hofman 1991).

Most reports have suggested the association between DAT and female gender (Andersen et al. 1999, Copeland et al. 1999a). However, new studies are required, since some reports are discrepant (Lobo et al. 1995, Sandberg et al. 2001). Similarly, in support of the "cognitive reserve hypothesis" (Qiu et al. 2001), most studies, including ours (Lobo et al. 1995), have also reported a striking association between DAT and low education (Letenneur et al. 1999). However, it remains to be determined to what extent other factors may influence the risk. For example, age has been reported to modify the risk atributed to female sex (Ott et al. 1998, Ruitenberg et al. 2001); and sex (Ott et al. 1999) or social factors (Meguro et al. 2001) have been reported to modify the risk attributed to low education.

In view of insufficient or contradictory findings, new research should also be performed to clarify at a population level the role that other factors may play in the cause of DAT (Slooter et al. 1998, Lindsay et al. 2002). Such factors may be biological, such as head injury, alcohol or tobacco consumption, Parkinson's disease, estrogen deficiency in women or abuse of some legal drugs, including anaesthesia before the age of 50 years; or factors recently considered, such as medical comorbidity (Doraiswamy et al. 2002) or exposition to potentially toxic products, in particular products that may be plausible biological factors (Tyas et al. 2001). Potential risk factors to investigate may also be psychosocial, and include social problems, living in rural areas, problems in early-life and adolescent environment, life style or social environment, or the impact of nursing home placement (Moceri et al. 2000, Smith et al. 2000, Lee et al. 2002). The protective effect of non-steroid anti-inflamatory drugs (NSAIDS), wine consumption or coffee consumption or regular physical activity also needs clarification (Lindsay et al. 2002). Finally, the contribution to DAT of the classical risk factors for vascular diseases is one of the most promising findings, (Stewart et al. 1999, Meyer et al. 2000a), particularly in relation to late-onset DAT (Kalman et al. 1999), but these studies require replication. Similarly, the potential protective role of antihypertensive medication in DAT is most promising (in't Veld et al. 2001), but confirmatory studies are required.

There is also abundant research evidence to support new studies to document the 
association between hypothesized risk factors and vascular dementia (VD). While the importance of risk factors such as hypertension, diabetes, apolipoprotein-epsilon 4, transient ischaemic attacks (TIA), hyperlipidemia or smoking tends to be confirmed in recent reports (Meyer et al. 2000a, Meyer et al. 2000b), new studies are needed to confirm the suggested modulating effects of factors such as gender (Hebert et al. 2000). Most studies have reported that VD is more frequent in men (Di Carlo et al. 2002, Copeland et al. 1999a, Ruitenberg et al. 2001), but some are discrepant (Hebert et al. 2000). New studies should also try to confirm the potential risk for VD of other factors suggested by recent research, such as living in a rural area or in institutions, depression, occupational exposure to fertilizers or fumigants (Hebert et al. 2000); or the protective effect of factors such as taking antihypertensive agents (Guo et al. 2001, in't Veld et al. 2001) or regular exercise for women (Hebert et al. 2000).

\section{Methodological standards in psychiatric epidemiology in the elderly}

The experience with epidemiological studies of dementia suggests the importance of maintaining good methodological standards (Launer et al. 1992a, Riedel-Heller et al. 2001). It is now clear that both, prevalence and incidence studies of dementia should investigate representative community samples which include institutionalized and non-institutionalized elderly. Standardized structured methods of screening and case ascertaintment instruments specifically developed for the elderly should be used (Andersen et al. 1999), and the cut-off points individualized and previously tested in the specific culture (Lobo et al. 1995). Similarly, standardized diagnostic criteria and case levels of illness are now commonly required (Black et al. 1990, Riedel-Heller et al. 2001).

In studying risk factors, case-control studies may be powerful, and are classical in this field (van Duijn and Hofman 1991). However, conclusions of studies based on hospital cases or on population, prevalent cases should previously discuss potential selection or information bias. At the time the ZARADEMP Project and other studies of the EURODEM Workgroup were designed, it was generally agreed that there is a need for case-control studies based on incident cases of dementia to adequately assess risk factors (Launer et al. 1992b, Lobo et al. 1992). Furthermore, special techniques may be required in data analysis. Latent variable analysis suggests that some potential risk factors of dementia are positively correlated with each other and could be conceptualised as correlated, observable manifestations of more unitary underlying constructs (Liu et al. 2001).

\section{New inquiries into the epidemiology of depression in the elderly}

There are also reasons to support the inclusion of new studies of depression in a community investigation of dementia, and some of them will be reviewed here. While prevalence studies are abundant, new studies are needed to document the age and sex specific incidence of depression (Green et al. 1992, Jorm 1995). In relation to risk factors, the association between depression and factors such as social problems has been 
consistently found in different studies (Kopp et al. 2000, Ostler et al. 2001). Similarly to most reports, depressive conditions in ZARADEMP 0 were higher in women when compared to men (Weissman and Klerman 1985), and also in lower educational levels (Weissman et al. 1991, Lobo et al. 1995). Furthermore, we reported during the same investigation wide differences of prevalence of both, depression and depressive symptoms between our city and other European cities (Copeland et al. 1999b, Copeland et al. 1999c), and the influence of social and environmental factors was suggested. By itself, however, this association does not reveal a causal connection, since social problems have also been reported as a consequence of depression (Van Hook 2003). Other suggested risk factors for depression include life insatisfaction, loneliness, recent life events (Green et al. 1992) or disability (Cole and Dendukuri 2003), or new factors such as smoking (Jorm 1999). Further inquiry is essential before firm conclusions may be drawn in relation to both, social causes and social consequences of depression, since support from prospective studies and from case-control studies is limited (Conwell et al. 2002). The issue may be clarified in a community study such as the ZARADEMP Project.

An overlap between dementia and depression was also reported in ZARADEMP 0 , but a complex, multi-facetted relationships between both conditions has been described by different authors (Mahendra 1985, Rao 2000, Harwood et al. 2000). We challenged the notion put forward by some authors (Hendricksen et al. 2004) about the possibility that in the elderly they might be common conditions due to dysfunction in an aging brain, since contrary to dementia, the prevalence rate of depression did not increase systematically with age (Lobo et al. 1995). Fur- thermore, our data did not support an age effect on the comorbidity found, but authors such as Ames (1990) have questioned the validity of the distinction in the very old in view of the overlap and the poor outcome of patients diagnosed as depressed (Sharma et al. 1998, Saz et al. 1999). Specifically, one of the objectives in the ZARADEMP Project was to document to what extent depression has an increased risk for DAT (Jorm 2000, Weiner et al. 2002), rather than being a prodromal or early manifestation of dementia or an emotional, adjustment reaction to the awareness of the illness (Wetherell et al. 1999, McDowell 2001). Among all disciplines involved in the epidemiological study of dementia, psychiatry is in a unique position to investigate this subject.

\section{Other objectives of the project: cross-cultural comparisons}

Other objectives of the study were to document: a) the course and natural history of both dementia and depression in this population, aiming at the identification of subtypes which might suggest different aetiopathogenetic mechanisms or different intervention strategies (Jagger et al. 2000, Dartigues 1999); b) the prevalence, incidence and associations of disability; c) the prevalence, incidence and implications of physical morbidity, as well as non-cognitive, non-depressive morbidity; and d) the mortality outcomes and factors influencing them, in an attempt to replicate in larger samples, and controlling for methodological problems, the findings in previous studies (Sharma et al. 1998), including ours (Saz et al. 1999). The database could also be used in the future to test in this cohort of 
the elderly new hypotheses related to advances in the field of dementia and depression.

Finally, the ZARADEMP Project was designed to compare incidence rates of dementia, as well as depression, and risk factors for both conditions found in Zaragoza with data reported using the same methods in other European cities during the EURODEM (Launer et al. 1992b) and EURODEP (Copeland et al. 1999b) studies respectively. Differences found in prevalence rates of both dementia (Lobo et al. 2000) and depression (Copeland et al. 1999c) in these previous reports, which include preliminary data from Zaragoza, are encouraging, since substantial epidemiological reasoning would be prompted if crossnational differences are confirmed. However, prevalence studies may be influenced by duration and fatality rates. Therefore, comparative studies of incidence rates have more epidemiological interest. In relation to this, geographical differences have also been suggested in indicence reports of dementia (Jorm and Jolley 1998, Waite et al. 2001, Chandra et al. 2001), even when a common design was used in the participating centers (Fratiglioni et al. 2000). Preliminary data from Zaragoza were also included in this last study, and now require confirmation.

Specific hypotheses for each objective have been formulated, and will be presented and discussed in the coming papers.

\section{Acknowledgements}

Supported by grants $94-1562,97-1321 \mathrm{E}$, 98-0103 and 01-0255 from the Fondo de Investigación Sanitaria, Ministerio de
Sanidad, Madrid, Spain, by grant CICYT SAF93-0453 from the Dirección General de Investigación científica y Técnica, Secretaría General de Universidades, Madrid, and by grants from the Fundación CAI and Fundación Pfizer.

The following researchers from the ZARADEMP Workgroup are also authors in this paper: Quintanilla MA, Quetglas B, Zapata M, Martín A, Gurrea A, Sarasola A, Pelegrín C, Pascual A, Campos R, Alonso JP, Astier P, Morales F, Pascual LF, Salvador JA, Lacámara C, Laguardia P.

The authors acknowledge the contribution of the medical students and general practitioners, who participated in the field study as lay interviewers.

We also thank Robert G Robinson, at the Department of Psychiatry, Iowa University, USA, and John RM Copeland, at the Department of Psychiatry, University of Liverpool, United Kingdom, for their encouragement and helpful criticisms of the final draft of this article.

\section{References}

Ames D, Dolan R, Mann A. The distinction between depression and dementia in the very old. Int J Geriatr Psychiatry 1990; 5: 193-198.

Andersen K, Launer LJ, Dewey ME et al. Gender differences in the incidence of $\mathrm{AD}$ and vascular dementia: The EURODEM Studies. EURODEM Incidence Research Group. Neurology 1999; 53(9): 1992-1997.

Black SE, Blessed G, Edwarson JA et al. Prevalence rates of dementia in an ageing population: Are low rates due to the use of insensitive instruments? Age Ageing 1990; 19: 84-90.

Chandra V, Pandav R, Dodge HH et al. Incidence of Alzheimer's disease in a rural community in India: the Indo-US study. Neurology 2001; 57(6): 985-989. 
Cole MG, Bellavance F, Mansour A. Prognosis of depression in elderly community and primary care populations: a systematic review and meta-analysis. Am J Psychiatry 1999; 156(8): 1182-1189.

Cole MG, Dendukuri N. Risk factors for depression among elderly community subjects: a systematic review and meta-analysis. Am J Psychiatry 2003; 160(6): 11471156.

Conwell Y, Duberstein PR, Caine ED. Risk factors for suicide in later life. Biol Psychiatry 2002; 52(3): 193-204.

Copeland JR, McCracken CF, Dewey ME et al. Undifferentiated dementia, Alzheimer's disease and vascular dementia: age- and gender-related incidence in Liverpool. The MRC-ALPHA Study. Br J Psychiatry 1999a; 175: 433-438.

Copeland JRM, Beekman ATF, Dewey ME et al. Depression in Europe: Geographical distribution among older people. Br J Psychiatry 1999b; 174: 312-321.

Copeland JRM, Beekman ATF, Dewey ME et al. Crosscultural comparison of depressive symptoms in Europe does not support stereotypes of ageing. Br J Psychiatry 1999c; 174: 322-329.

Copeland JRM, Dewey ME, Wood N et al. Range of mental illness amongst the elderly in the community: prevalence in Liverpool using the GMS-AGECAT package. Br J Psychiatry 1987; 150: 815-823.

Dartigues JF. Dementia: epidemiology, intervention and concept of care. Z Gerontol Geriatr 1999; 32: 407-411.

Di Carlo A, Baldereschi M, Amaducci L et al. (ILSA Working Group). Incidence of dementia, Alzheimer's disease and vascular dementia in Italy. The ILSA Study. $J$ Am Geriatr Soc 2002; 50(1): 41-48.

Doraiswamy PM, Leon J, Cummings JL et al. Prevalence and impact of medical comorbidity in Alzheimer's disease. J Gerontol A Biol Sci Med Sci 2002; 57(3): M173177.

Fratiglioni L, Launer LJ, Andersen K et al. Incidence of dementia and major subtypes in Europe: A collaborative study of population-based cohorts. Neurologic Diseases in the Elderly Research Group. Neurology 2000; 54(11 Suppl 5): S10-S15.

Gao S, Hendrie HC, Hall KS et al. The relationships between age, sex, and the incidence of dementia and Alzheimer disease: a meta-analysis. Arch Gen Psychiatry 1998; 55(9): 809-815.

Green BH, Copeland JRM, Dewey ME et al. Risk factors for depression in elderly people: A prospective study. Acta Psychiatr Neurol Scand 1992; 86(3): 213-217.
Guo Z, Fratiglioni L, Viitanen M et al. Apolipoprotein E genotypes and the incidence of Alzheimer's disease among persons aged 75 years and older: variation by use of antihypertensive medication? Am J Epidemiol 2001; 153(3): 225-231.

Harwood DG, Barker WW, Ownby RL et al. Depressive symptoms in Alzheimer's disease. An examination among community dwelling Cuban American patients. Am J Geriatr Psychiatry 2000; 8: 84-91.

Hebert R, Lindsay J, Verreault R et al. Vascular dementia : incidence and risk factors in the Canadian study of health and aging. Stroke 2000; 31(7): 1487-93.

Hendricksen M, Thomas AJ, Ferrier IN et al. Neuropathological study of the dorsal raphe nuclei in late-life depression and Alzheimer's disease with and without depression. Am J Psychiatry 2004; 161(6): 1096-1102.

Hofman A, Rocca WA, Brayne C et al, for the European Prevalence Research Group. The prevalence of dementia in Europe. A collaborative study of 1980-1990 prevalence findings. Int J Epidemiol 1991; 20 (3): 736-748.

in't Veld BA, Ruitenberg A, Hofman A et al. Antihypertensive drugs and incidence of dementia: the Rotterdam Study. Neurobiol Aging 2001; 22(3): 407-412.

Jagger C, Andersen K, Breteler MMB et al, for the Neurologic Diseases in the Elderly Research Group. Prognosis with dementia in Europe: A collaborative study of population-based cohorts. Neurology 2000; 54(Supl 5): S16-S20.

Jorm AF. The epidemiology of depressive states in the elderly: implications for recognition, intervention and prevention. Soc Psychiatry Psychiatr Epidemiol 1995; 30(2): 53-59.

Jorm AF, Jolley D. The incidence of dementia: a metaanalysis. Neurology 1998; 51(3): 728-733.

Jorm AF, Korten AE, Henderson AS. The prevalence of dementia: A quantitative integration of the literature. Acta Psychiatr Neurol Scand 1987; 76: 465-479.

Jorm AF. Association between smoking and mental disorders: results from an Australian National Prevalence Survey. Aust N Z J Public Health 1999; 23(3): 245-248.

Jorm AF. Is depression a risk factor for dementia or cognitive decline? A review. Gerontology 2000; 46: 219-227.

Kalman J, Kudchodkar BJ, Murray K et al. Evaluation of serum-lipid-related cardiovascular risk factors in Alzheimer's disease. Dement Geriatr Cogn Disord 1999; 10(6): 488-493.

Kopp MS, Skrabski A, Szedmak S. Psychosocial risk factors, inequality and self-rated morbidity in a changing society. Soc Sci Med 2000; 51(9): 1351-1361. 
Launer LJ, Brayne C, Breteler MMB. Epidemiologic approach to the study of dementing diseases: A nested case-control study in European incidence studies of dementia. In: Launer LJ, Brayne C, Dartigues JF, Hofman A, eds. European studies on the incidence of dementing diseases. A report of the EURODEM Research Group. Neuroepidemiology 1992a; 11(Supplement 1): 114-118.

Launer LJ, Brayne C, Dartigues JF et al. European studies on the incidence of dementing diseases. A Report of the EURODEM Research Group. Neuroepidemiology 1992b; 11(suppl 1): 1-22.

Lee DY, Lee JH, Ju YS et al. The prevalence of dementia in older people in an urban population of Korea: the Seoul study. Am J Geriatr Psychiatry 2002; 50(7): 12331239.

Letenneur L, Gilleron V, Commenges D et al. Are sex and educational level independent predictors of dementia and Alzheimer's disease? Incidence data from the PAQUID project. J Neurol Neurosurg Psychiatry 1999; 66(2): 177183.

Lindsay J, Laurin D, Verreault R et al. Risk factors for Alzheimer's disease: a prospective analysis from the Canadian Study of Health and Aging. Am J Epidemiol 2002; 156(5): 445-453.

Liu SJ, Crum RM, Anthony JC. A latent variable approach to studying risk factors for Alzheimer's disease. Neuroepidemiology 2001; 20(1): 31-9.

Lobo A, Launer LJ, Fratiglioni L, et al: Prevalence of dementia and major subtypes in Europe: A collaborative study of population-based cohorts. Neurology 2000; 54(Supl 5): 4-9.

Lobo A, Saz P, Marcos G et al. The prevalence of dementia and depression in the elderly community in a Southern European population: the Zaragoza study. Arch Gen Psychiatry 1995; 52: 497-506.

Lobo A, Saz P, Marcos G, et al: The Zaragoza Study: Dementia and depression in the elderly community. Barcelona: Editorial Masson Salvat S.A., 1997.

Lobo A, Saz P, Marcos G et al. Incidence of dementia and other psychiatric conditions in the elderly: Zaragoza study. In: Launer LJ, Brayne C, Dartigues JF, Hofman A, eds. European studies on the incidence of dementing diseases. A report of EURODEM Research Group. Neuroepidemiology 1992; 11(Suppl 1): 52-56.

Mahendra B. Depression and dementia: the multifaceted relationship. Editorial, Psychol Med 1985; 15(2): 227-236.

McDowell I: Alzheimer's disease: insights from epidemiology. Aging 2001; 13: 143-162.
McGee MA and Brayne C. Exploring the impact of prevalence and mortality on incidence of dementia in the oldest old: the sensitivity of a deterministic approach. Neuroepidemiology 2001; 20(4): 221-224.

Meguro K, Meguro M, Caramelli P et al. Elderly Japanese emigrants to Brazil before World War II: II. Prevalence of senile dementia. Int J Geriatr Psychiatry 2001; 16(8): 775-779.

Mellow AM (ed.). Geriatric Psychiatry (Review of Psychiatry Services, vol. 22, number 4; Oldham JM and Riba MB, series editors). Washington D.C.: American Psychiatric Press, 2003.

Meyer JS, Rauch G, Rauch RA et al. Risk factors for cerebral hypoperfusion, mild cognitive impairment, and dementia. Neurobiol Aging 2000b; 21(2): 161-169.

Meyer JS, Rauch GM, Rauch RA et al. Cardiovascular and other risk factors for Alzheimer's disease and vascular dementia. Ann N Y Acad Sci 2000a; 903: 411-423.

Moceri VM, Kukull WA, Emanuel I et al. Early-life risk factors and the development of Alzheimer's disease. Neurology 2000; 54(2): 415-420.

Ostler K, Thompson C, Kinmonth AL et al. Influence of socio-economic deprivation on the prevalence and outcome of depression in primary care: the Hampshire Depression Project. Br J Psychiatry 2001; 178(1): 12-17.

Ott A, Breteler MM, van Harskamp F et al. Incidence and risk of dementia. The Rotterdam Study. Am J Epidemiol 1998; 147(6): 574-80.

Ott A, van Rossum CT, van Harskamp F et al. Education and the incidence of dementia in a large population-based study: the Rotterdam Study. Neurology 1999; 52(3): 663666.

Petersen RC, Stevens JC, Ganguli M et al. Practice parameter: early detection of dementia: mild cognitive impairment (an evidence-based review). Report of the Quality Standards Subcommittee of the American Academy of Neurology. Neurology 2001; 56(9): 1133-1142.

Qiu C, Backman L, Winblad B et al. The influence of education on clinically diagnosed dementia incidence and mortality data from the Kungsholmen Project. Arch Neurol 2001; 58(12): 2034-2039.

Rao R. Cerebrovascular disease and late life depression: an age old association revisited. Int J Geriatr Psychiatry 2000; 15: 419-433.

Riedel-Heller SG, Busse A, Aurich C et al. Prevalence of dementia according to DSM-III-R and ICD-10: results of the Leipzig Longitudinal Study of the Aged (LEILA75+) Part 1. Br J Psychiatry 2001; 179: 250-254. 
Rocca WA, Cha RH, Waring SC et al. Incidence of dementia and Alzheimer's disease: a reanalysis of data from Rochester, Minnesota, 1975-1984. Am J Epidemiol 1998; 148(1): 51-62.

Ruitenberg A, Ott A, van Swieten JC et al. Incidence of dementia: does gender make a difference? Neurobiol Aging 2001; 22(4): 575-580.

Sandberg G, Stewart W, Smialek J et al. The prevalence of the neuropathological lesions of Alzheimer's disease is independent of race and gender. Neurobiol Aging 2001; 22(2): 169-175.

Saz P, Launer LJ, Día JL et al. Mortality and mental disorders in a Spanish elderly population. Int J Geriatr Psychiatry 1999; 14: 1031-1038.

Sharma VK, Copeland JR, Dewey ME et al. Outcome of the depressed elderly living in the community in Liverpool: a 5-year follow-up. Psychol Med 1998; 28(6): 132937.

Slooter AJ, Cruts M, Kalmijn S et al. Risk estimates of dementia by apolipoprotein E genotypes from a population-based incidence study: the Rotterdam Study. Arch Neurol 1998; 55(7): 964-968.

Smith GE, Kokmen E, O'Brien PC. Risk factors for nursing home placement in population-based dementia cohort. J Am Geriatr Soc 2000; 48(5): 519-525.

Stewart R, Prince M, Mann A. Vascular risk factors and Alzheimer's disease. Aust N Z J Public Health 1999; 33(6): 809-813.

Tyas SL, Manfreda J, Strain LA et al. Risk factors for Alzheimer's disease: a population-based, longitudinal study in Manitoba, Canada. Int J Epidemiol 2001; 30(3): 598-599.
Van Duijn CM, Hofman A, eds. Risk factors for Alzheimer's disease: A collaborative re-analysis of casecontrol studies. Int J Epidemiol 1991; 20(Suppl 2).

Van Hook MP. Psychosocial issues within primary health care settings: challenges and opportunities for social work practice. Soc Work Health Care 2003; 38(1): 63-80.

Waite LM, Broe GA, Grayson DA et al. The incidence of dementia in an Australian community population: the Sydney Older Persons Study. Int J Geriatr Psychiatry 2001; 16(7): 680-689.

Weiner MF, Doody RS, Sairam R et al. Prevalence and incidence of major depressive disorder in Alzheimer's disease: findings from two databases. Dement Geriatr Cogn Disord 2002; 13(1): 8-12.

Weissman MM, Bruce ML, Leaf PJ et al. Affective disorders. In: Robins LN, Regier DA, eds. Psychiatric disorders in America. New York: The Free Press 1991, 53-80.

Weissman MM, Klerman GL. Gender and depression. Trends Neurosci 1985; 8: 416-420.

Wetherell JL, Gatz M, Johansson B et al. History of depression and other psychiatric illness as risk factors for Alzheimer disease in a twin sample. Alzheimer Dis Assoc Disord 1999; 13(1): 47-52.

Address of correspondence:

Dr. Antonio Lobo

Servicio de Psiquiatría

Hospital Clínico Universitario, planta 3

Avda. San Juan Bosco, 15

50009 Zaragoza

SPAIN 